\title{
Characterization of Minimum Impeller Speed for Suspension of Solids in Liquid at High Solid Concentration, Using Gamma-Ray Densitometry
}

\author{
Rouzbeh Jafari, Philippe A. Tanguy, and Jamal Chaouki \\ Department of Chemical Engineering, École Polytechnique de Montréal, P.O. Box 6079, Station Centre-Ville, \\ Montreal, QC, Canada H3C $3 A 7$ \\ Correspondence should be addressed to Jamal Chaouki, jamal.chaouki@polymtl.ca \\ Received 28 February 2012; Accepted 21 April 2012 \\ Academic Editor: See-Jo Kim
}

Copyright (๑) 2012 Rouzbeh Jafari et al. This is an open access article distributed under the Creative Commons Attribution License, which permits unrestricted use, distribution, and reproduction in any medium, provided the original work is properly cited.

\begin{abstract}
The successful design and operation of Liquid-Solid (LS) and Gas-Liquid-Solid (GLS) stirred tank reactors requires an accurate determination of the level of solid suspension needed for the process at hand. A poor design of the stirred tank to achieve optimum conditions and maintain the system under these conditions during operation may cause significant drawbacks concerning product quality (selectivity and yield) and cost. In this paper, the limitations of applying conventional measurement techniques for the accurate characterization of critical impeller speed for just off-bottom suspension $\left(N_{\mathrm{JS}}\right)$ at high solid concentrations are described. Subsequently, the Gamma-Ray Densitometry technique for characterizing $N_{\text {IS }}$ is introduced, which can overcome the limitations of previous experimental techniques. The theoretical concept of this method is explained, and experimental validation is presented to confirm the accuracy of the Gamma-Ray Densitometry technique. The effects of clearance, scale, and solid loading on $N_{\text {IS }}$ for several impellers are discussed. Experimental $N_{\text {JS }}$ values are compared with correlations proposed in the literatures, and modifications are made to improve the prediction. Finally, by utilizing the similarity to the incipient movement of solid particles in other systems, a theoretical model for $N_{\text {IS }}$ prediction is presented.
\end{abstract}

\section{Introduction}

Maximum solid-liquid contact is essential for the optimization of many chemical processes. Contact modes include solid dispersion, dissolution, leaching, crystallization, precipitation, adsorption, ion exchange, solid-catalyzed reaction, and suspension polymerization. In many processes (especially dissolution, leaching and solid-catalyzed reactions), the main objective of liquid-solid contacting is to maximize the surface area of the solid particles available for reaction or transport processes (heat and/or mass transfer). This can only be achieved by optimizing hydrodynamic conditions where solid particles move freely and do not accumulate at any point in the vessel. Under these conditions, the system can be described to be under "just off-bottom suspension or just-suspended" conditions.

Inside a reaction vessel, solid particles in a liquid medium tend to settle towards the bottom as their density is usually higher than that of the liquid. In this scenario, an external force is necessary to lift the solids and retain them in a suspended state. Depending on the unit operation at hand, this force can be provided through various techniques such as agitation in stirred tanks or gas sparging in three-phase fluidized beds. The energy input creates a turbulent flow field that lifts the solid particles from the vessel base and disperses them throughout the liquid. Solids pickup from the vessel base is achieved by a combination of (1) the drag and lift forces of the moving fluid on the solid particles and (2) the burst of turbulent eddy created in the flow bulk.

Stirred tanks have been used in the chemical process industry for decades. The energy input provided by the rotating impeller enhances mass and heat transfer rate compared to other types of contactors. For liquid-solid (LS) stirred tank, mass transfer rate is increased by increasing impeller speed. However, two contrasting trends can be observed; at impeller speeds lower than just-suspended condition, mass 
transfer clearly increases with higher impeller speeds. On the other hand, the observed rate may not increase significantly with impeller speed or mixing intensity beyond the justsuspended condition. This indicates that operating at justsuspended conditions is the minimum requirement for processes where mass transfer is controlling the process [1]. It is, therefore, important to define what level of suspension is required versus the desired process results. While just-suspended condition is optimal condition for many processes, a high degree of suspension is required for crystallization or slurry feed system. For the dissolution of highly soluble solids, partial suspension is sufficient. Failure to operate at optimal condition due to uncertainty in predicting the impeller speed required to achieve and maintain the just-suspended condition leads to considerable drawbacks. If a mixing system operates above the minimum speed for solid suspension, the degree of suspension will be improved and the mass transfer rate will be enhanced. Higher speed, however, yields a higher turbulence shear rate, which for some processes, that is, biological processes, may cause undesirable particle attrition or cell mortality. Obviously, there is also a practical economic limit on the maximum speed of agitation. For example, in the gold cyanidation process, where a high concentration slurry (up to 50\% $\mathrm{wt} / \mathrm{wt}$ ) is processed to achieve a high production rate of gold, operating at an impeller speed lower than the justsuspended condition will generate fillets in the vessel, thereby detrimentally affecting the reaction selectivity and yield. In some cases, a small proportion of particles may be allowed to accumulate in corners or on the bottom in relatively stagnant regions to form fillets. This condition may offer advantages from the practical point of view because of a large savings in energy consumption compared to what is required for complete suspension. This energy savings may be more than the effect of the loss of active solids. However, it is important to quantitatively define what portion of solid is left unsuspended. On the other hand, overprediction of $N_{\text {JS }}$ causes significant economical drawbacks. For example, in the gold cyanidation process, 5 to $50 \%$ overprediction of $N_{\text {IS }}$ leads to $\$ 150,000$ to $\$ 2,200,000 /$ year in supplementary energy expenses. Also, the added cost for the purchase, installation, and maintenance of larger mechanical parts should be considered. This extra capital and operating costs cannot be compensated by additional gold recovered from the process. Furthermore, comprehensive knowledge about the effect of different factors (physical properties, geometrical and operational parameters) is central to the proper design and operation of LS-stirred tank reactors. Although characterizing $N_{\mathrm{JS}}$ was the subject of much research and many published scientific contributions, the subjectivity of conventional measurement techniques leads to a high degree of uncertainty in the prediction of $N_{\text {IS. It }}$. was shown that a significant variance appears in the prediction of $N_{\mathrm{JS}}$, and there is no correlation with universal validity. Bohnet and Niesmak [2] calculated the critical impeller speed of the suspension using nine correlations and found that the reported values were in the range of $-56 \%$ to $+250 \%$ from their own values. In addition, only a few studies deal with high concentration solid suspensions in stirred tanks and current experimental methods show their limitations in terms of accuracy. For the design of concentrated systems, it is important to develop more reliable techniques for characterizing just-suspended speed. In this work, the Gamma-Ray Densitometry technique is proposed. It will be shown that this new technique minimizes the subjectivity of $N_{\text {JS }}$ characterization techniques and is not affected by the mixing system.

\section{Background}

At constant loading of solid particles, if the impeller speed is increased incrementally, bottom particles become increasingly suspended and the fraction of settled solids decreases. Upon reaching a specific impeller speed, all settled particles are continuously in motion on the tank bottom before becoming suspended. The bottom motion prior to suspension may involve a fraction of the settled solids coming to a brief rest before departing from the bottom into suspension. With a slight increase in impeller speed, this stoppage of solid particles is eliminated and particle-bottom contact time is shortened. The impeller speed at which this phenomenon occurs is defined as the critical impeller speed required for solid suspension $\left(N_{\mathrm{SS}}\right)$. The earliest and most common method for characterizing $N_{\text {JS }}$ is the visual technique. Zwietering [3] proposed a visual observation method to determine $N_{\text {IS. }}$. The motion of the solid particles was observed through the wall and bottom of transparent tank using a mirror placed directly underneath it. $N_{\text {IS }}$ was defined as the impeller speed at which no solids remain on the tank bottom for more than 1 or 2 seconds. This method allows determining $N_{\text {JS }}$ with an accuracy of $\pm 5 \%$ for the same observer.

However, only with careful observation it is possible to achieve $\pm 5 \%$ reproducibility in a diluted suspension. Furthermore, visual methods require a transparent vessel, which is feasible for most laboratory-scale studies, but rather complicated for large-scale vessels. To overcome the limitations of the visual technique, other methods have been proposed. In Table 1, experimental methods for characterizing $N_{\text {IS }}$ have been listed. Their limitations and advantages have been explained and they are ranked based on their accuracy and applicability. Those experimental techniques were applied to numerous empirical and semiempirical investigations on solid suspension, whose results were critically reviewed in the literature (e.g., $[6,12])$. To provide more insight about the suspension mechanism, researchers have introduced theoretical models to predict $N_{\text {IS }}$. These models are generally classified into different categories. The first category describes particle pickup by turbulent eddies [13], while with the second category, particles are assumed to be picked up by fluid flow [14]. There also exists a third category in which a suspension model is based on analogy to other multiphase systems, like minimum fluidization of the gas-liquid-solid fluidized beds $[15,16]$. Theoretical methods are listed and explained in Table 2. Although these theoretical methods are applicable for a first estimation of operating conditions, most of these methods still require empirical characterization of some parameters. There have been few efforts to predict $N_{\text {JS }}$ by means of commercial CFD codes 
TABLE 1: Experimental methods for characterizing $N_{\text {JS }}$ (adapted from $[1,4]$ ).

\begin{tabular}{|c|c|c|c|c|c|}
\hline $\begin{array}{l}\text { Method } \\
\text { proposed by }\end{array}$ & Concept & Advantages & Disadvantages & Applicability & Accuracy \\
\hline Zwietering [3] & $\begin{array}{l}\text { Visual observation of } \\
\text { particles that do not rest } \\
\text { at the vessel bottom for } \\
\text { more than } 1-2 \mathrm{sec}\end{array}$ & $\begin{array}{l}\text { Simplicity, } \\
\text { nonintrusive }\end{array}$ & $\begin{array}{l}\text { Not applicable for opaque sys- } \\
\text { tem, high uncertainty for high } \\
\text { solid loading systems, careful and } \\
\text { skilled observation is necessary }\end{array}$ & 1 & 3 \\
\hline $\begin{array}{l}\text { Mersmann et al. } \\
{[5]}\end{array}$ & $\begin{array}{l}\text { Visual observation of the } \\
\text { height of the slurry com- } \\
\text { pared to the total height }\end{array}$ & $\begin{array}{l}\text { Nonintrusive, } \\
\text { Simplicity }\end{array}$ & $\begin{array}{l}\text { Small particles suspended, come } \\
\text { to the top of the tank, results in } \\
\text { vanishing interface while larger } \\
\text { particles are still resting at the } \\
\text { bottom }\end{array}$ & 1 & 5 \\
\hline $\begin{array}{l}\text { Rewatkar et al. } \\
{[6]}\end{array}$ & $\begin{array}{l}\text { Variation of impeller } \\
\text { power consumption by } \\
\text { increasing the amount of } \\
\text { solid suspended }\end{array}$ & $\begin{array}{l}\text { Nonintrusive, can } \\
\text { be used for opaque } \\
\text { systems }\end{array}$ & $\begin{array}{l}\text { Requires accurate measurement } \\
\text { of power consumption, expensive } \\
\text { for large scale vessels, the criteria } \\
\text { are not clear }\end{array}$ & 3 & 5 \\
\hline $\begin{array}{l}\text { Rewatkar et al. } \\
{[6]}\end{array}$ & $\begin{array}{l}\text { Variation of liquid phase } \\
\text { mixing time by increas- } \\
\text { ing amount of solid sus- } \\
\text { pended }\end{array}$ & $\begin{array}{l}\text { Can be used for } \\
\text { opaque system }\end{array}$ & $\begin{array}{l}\text { Requires accurate measurement } \\
\text { of mixing time, not applicable for } \\
\text { large-scale vessels, the criteria are } \\
\text { not clear, in high solid loading } \\
\text { or three-phase systems, accurate } \\
\text { measurement of mixing time is } \\
\text { challenging }\end{array}$ & 3 & 5 \\
\hline $\begin{array}{l}\text { Rewatkar et al. } \\
{[6]}\end{array}$ & $\begin{array}{l}\text { Decrease in count rate } \\
\text { recorded from radioac- } \\
\text { tive tracer inside the ves- } \\
\text { sel by increasing impeller } \\
\text { speed }\end{array}$ & $\begin{array}{l}\text { Nonintrusive can } \\
\text { be used in opaque } \\
\text { system }\end{array}$ & $\begin{array}{l}\text { Decrease in recorded count rate } \\
\text { could be because of tracer disper- } \\
\text { sion not just off-bottom suspen- } \\
\text { sion } \\
\text { The criteria are not clear }\end{array}$ & 5 & 5 \\
\hline Musil et al. [7] & $\begin{array}{l}\text { Discontinuity in solid } \\
\text { concentration close to } \\
\text { the bottom of the vessel } \\
\text { by increasing impeller } \\
\text { speed }\end{array}$ & $\begin{array}{l}\text { Can be used in } \\
\text { opaque system }\end{array}$ & $\begin{array}{l}\text { Intrusive, accurate measurement } \\
\text { of concentration is challenging }\end{array}$ & 3 & 4 \\
\hline $\begin{array}{l}\text { Chapman et al. } \\
{[8]}\end{array}$ & $\begin{array}{l}\text { Peak in solid concentra- } \\
\text { tion measured close to } \\
\text { the bottom of the ves- } \\
\text { sel by increasing impeller } \\
\text { speed }\end{array}$ & $\begin{array}{l}\text { Can be used in } \\
\text { opaque system }\end{array}$ & $\begin{array}{l}\text { Intrusive accurate measurement } \\
\text { of concentration is difficult }\end{array}$ & 3 & 4 \\
\hline $\begin{array}{l}\text { Buurman et al. } \\
\text { [9] }\end{array}$ & $\begin{array}{l}\text { Use of Doppler effect at } \\
\text { vessel bottom }\end{array}$ & $\begin{array}{l}\text { Independent } \\
\text { of material and } \\
\text { scale, nonintrusive }\end{array}$ & $\begin{array}{l}\text { Applying the technique is chal- } \\
\text { lenging, ultrasound sensor must } \\
\text { be installed inside the vessel oth- } \\
\text { erwise signals are scattered by } \\
\text { wall }\end{array}$ & 4 & 2 \\
\hline $\begin{array}{l}\text { Micale et al. } \\
{[10,11]}\end{array}$ & $\begin{array}{l}\text { Change in the pressure } \\
\text { recorded at the bottom } \\
\text { of the vessel by increas- } \\
\text { ing impeller speed }\end{array}$ & $\begin{array}{l}\text { Independent of ma- } \\
\text { terial, nonintrusive }\end{array}$ & $\begin{array}{l}\text { Proper selection of pressure re- } \\
\text { cording port is important, meth- } \\
\text { od proposed to eliminate effect } \\
\text { of dynamic pressure head is not } \\
\text { accurate }\end{array}$ & 2 & 3 \\
\hline
\end{tabular}

Accuracy: 1: most accurate, 5: least accurate, Applicability: 1: easiest to apply, 5: most difficult to apply.

[17-21]. CFD tools could provide a valuable opportunity for studying solid suspension phenomena and characterizing $N_{\text {JS }}$ but the validity of computational methods in highly concentrated turbulent flow is still questionable.

Prediction of just suspended speed was the subject of few CFD studies [19, 21-23]. CFD simulations, if successfully applied, can be more quantitative and predictive than the empirical or theoretical correlations.
Lea [23] used a CFD-assisted design approach to study the effectiveness of mixing tank geometrical configurations to suspend particles. He developed a design heuristic that can be applied in process industries. Murthy et al. [19] used CFD simulation to study the effect of different parameters on just suspended speed in LS and GLS systems. Their study covers solid loading up to $15 \%(\mathrm{wt} / \mathrm{wt})$. Fletcher and Brown [22] studied the influence of the choice of turbulence 
TABLE 2: Theoretical methods for predicting $N_{\text {JS }}$.

\begin{tabular}{ll}
\hline Reference & Concept \\
\hline Kolar [29] & $\begin{array}{l}\text { Energy necessary to suspend particles equals the } \\
\text { energy dissipated by the particle moving at its }\end{array}$
\end{tabular}
terminal velocity in a still fluid

Baldi et al. [13]

Narayanan et al. [30]

Subbarao and Taneja [31]

Ditl and Rieger [32]

Musil and Vlk [33]

Ayazi Shamlou and

Zolfagharian [14]

Molerus and Latzel $[15,35]$

Wichterle [36]

Mersmann et al. [5]
Particles are picked up and kept suspended by turbulent eddies

Balance of vertical forces acting on particles

Balance of forces acting on particles

Same concept as Baldi et al. [13], solid particles are picked up by different sizes of eddies

Balance between liquid and particle kinetic energy

Proposed a model for estimation necessary conditions for incipient motion of solid particles based on average velocity of the liquid near the bottom of the vessel and forces acting on particles, like lift, drag, buoyancy, and weight resting at the bottom of the vessel

Solid suspension governed by two different mechanisms based on Archimedes number.

Region responsible for solid suspension is the wall boundary layer of the vessel

Difference between the terminal settling velocity of particle and velocity of the liquid

Power input dissipated by two phenomena: consumption of power to avoid settling and generating discharge flow for suspension
Remarks

In a turbulent fluid, the settling velocity of a particle is different from that in a still fluid. Very simple model, unable to precisely predict $N_{\text {JS }}$ Assumptions are more likely similar to homogenous suspension rather than just-suspended conditions

Cannot describe the effect of viscosity nor the effect of solid concentration.

Cannot describe why the impeller that creates mass circulations (PBT) is more effective for suspending particles than impeller which creates a lot of turbulence

Assumption of no slip between solid and liquid and homogenous distribution of solid particles is questionable.

Proposed for very diluted solid concentrations

Particle settling velocity was estimated from a correlation for the porosity of a liquid fluidized bed as a function of liquid velocity

Cannot describe the effect of viscosity nor the effect of solid concentration

Cannot describe why the impeller that creates mass circulations (PBT) is more effective for suspending particles than impeller which creates a lot of turbulence

The approach followed by them was rejected by Ditl and Rieger [34] because of mathematical mistakes

Model does not need any experimental adjustment, but the parameter describing solid arrangement is unknown

Requires accurate correlation for predicting shear rate at the boundary layer of the vessel

The ratio between $N_{\text {IS }}$ and settling velocity allows predicting $N_{\mathrm{JS}}$ easily

Values for $N_{\text {JS }}$ calculated by this method are highly underpredicted compared to experimental data. This could be because the correlations for fluctuating velocity at the bottom of the vessel are not accurate models on the prediction of solid suspension by means of commercial CFD codes. Kee and Tan [18] presented a new CFD approach for predicting $N_{\text {JS }}$ and characterized effect of D/T and $C / T$ on $N_{\text {JS }}$. Ochieng and Lewis [20] provided qualitative and quantitative insight into solid suspension by simultaneous investigations using CFD and LDV. In their work suspension studies have been carried out in a Nickel precipitation process and best simulation results were obtained for solid loading lower than 6\% [24] studied three different criteria to determine $N_{\text {JS }}$ based on CFD simulation results. Comparing simulation results with empirical correlation predictions is reasonable, yet they suggested examining solid velocity at the bottom of the vessel as proper criteria [25] provided a complete review on the CFD simulation of solid suspension in a stirred tank. They have explained important parameters to achieve accurate simulation and discussed different models and simulation approaches. Although extensive efforts have been 


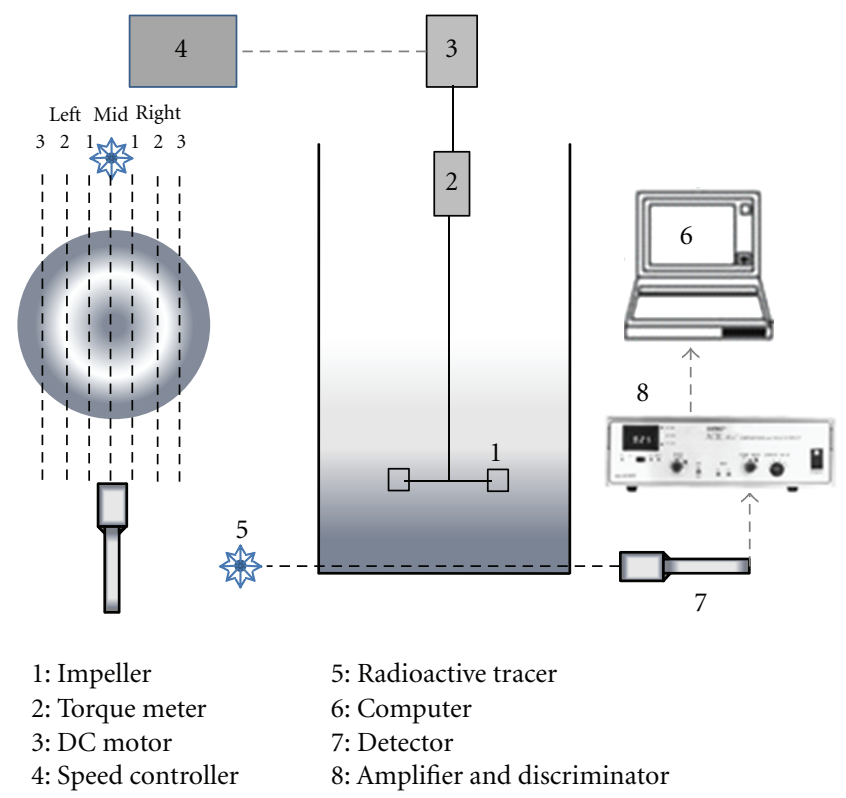

FIGURE 1: Experimental setup and gamma-ray densitometry data acquisition system.

made to apply CFD simulation to predict hydrodynamic parameters and the state of solid suspension in solid-liquid and gas-liquid-solid stirred tank reactors, it is commonly believed that turbulent models, which are being used for modeling a turbulent flow field in stirred tank reactors, have considerable uncertainties even in the single phase. Recently, [26] demonstrated that even in the single phase with current turbulent models, CFD results show errors up to $20 \%$ of the time. There are numbers of CFD works for liquid-solid stirred tank reactors, but they rarely have been validated for high solid concentration.

\section{Materials and Methods}

3.1. Experimental Setup. Experiments were conducted in $14 \mathrm{~L}$ and $58 \mathrm{~L}$ transparent polycarbonate cylindrical-stirred vessels with standard baffles, an open top and a flat bottom (Figure 1). Three different impellers were tested, mounted on a central shaft, namely, a six-blade Rushton turbine (RT), a concave blade turbine (CBT), and a four-blade pitched blade turbine in down-pumping mode (PBT-D). The vessel, impeller dimension, and geometrical details of the mixing system are given in Table 3 . Water was used as the liquid phase and sand as the solid phase (density of $2650 \mathrm{~kg} / \mathrm{m}^{3}$ ). Particle size distribution of sand was measured by the Horiba laser scattering particle size distribution analyzer (model: LA-950). The mean particle size was $277 \mu \mathrm{m}$. The operating slurry height was set equal to the vessel diameter.

3.2. Methods. The use of radioactive sources (radioisotopes) to characterize the fluid dynamics and hydrodynamics of single-phase and multiphase systems has an extensive history. A detailed review of these methods can be found in Chaouki et al. [27]. In the present work, we use the concept of densitometry described and applied above $[27,28]$ to
TABle 3: Design details of a mechanically stirred tank.

\begin{tabular}{ll}
\hline Parameter & Value \\
\hline Vessel diameter $(\mathrm{m})$ & 0.2 \\
$H / T$ & 1 \\
Baffle with & $\mathrm{T} / 10$ \\
Number of baffles & 4 \\
Material of construction & Plexiglass \\
Geometry & Cylindrical with flat bottom \\
Impeller clearance from & Varies between 0.5T to 0.2T \\
the bottom & RT (6 blade), D:T/3, W/D: $1 / 5$ \\
& CBT (6 blade), D:T/3, W/D: $1 / 5$ \\
Impellers & PBT (4 blade @ 45 $),$ D:T/3, W/D: $1 / 5$ \\
\hline
\end{tabular}

propose a new technique for characterizing $N_{\text {JS }}$. If a radioactive source is placed on one side of the vessel and a detector on the other side, based on the material between them the detector receives a specific amount of gamma ray. This phenomenon can be modeled by the Beer-Lambert's law that describes the decay in intensity of the emitted gamma ray by passing through the medium: $I=I_{0} \cdot \exp (-\rho \mu l)$. Changes in the density or phase of the medium lead to corresponding changes in the gamma-ray intensity recorded by the detector. In multiphase systems, the ray intensity is related to the volume fraction of each phase. This gammaray emission-obstruction-detection framework could be the basis of a useful tool for characterizing solid suspension in stirred tanks.

In practice, a source of gamma ray (a $2 \mathrm{~mm}$ glass bead filled with scandium oxide) was activated in the Slowpoke nuclear reactor of Ecole Polytechnique of Montreal. The source activity was between $100-200 \mu \mathrm{Ci}$, and the half-life 
time of the tracer was 84 days. The tracer was placed in the holder where it was completely shielded by lead. Emitted gamma rays from this source were collimated by lead support. It passed through a $5 \mathrm{~mm}$ hole on the protection shield and went through the vessel. A NaI scintillation detector (Teledyne Isotope, Model S-1212-I) was placed on the other side of the vessel and coupled to an amplifier (EG\&G ORTEC Model: 925-SCINT) and a data acquisition system (TOMO MSC plus-17)-See Figure 1. Both tracer and detector were positioned in order to be able to scan the region about $0.5 \mathrm{~cm}$ from the bottom of the vessel. The signals were recorded for 2 minutes with a $200 \mathrm{msec}$ sampling time at each impeller speed (varied between 0 to $1000 \mathrm{rpm}$ with different step sizes). Counts were recorded at each impeller speed, and they were converted and processed by home-made codes. It was verified that changing the sampling time and recording period as well as the background noise did not alter the experimental results. The original recorded count rates were related to the solid volume fraction. For this purpose, the same region was scanned without solids (pure water (1)). According to this procedure, the following equations can be established. Equation (4) relates the measured intensity to solid hold-up

$$
\begin{aligned}
& I_{\text {water only }}=I_{0} \exp \left(-\rho_{\text {water }} \mu_{\text {water }} L\right) \cdot \exp (-A) \text {, } \\
& I_{\text {liquid-solid }(N=0)}=I_{0} \exp \left(-\rho_{\text {water }} \mu_{\text {water }} L\left(1-\epsilon_{s, 0}\right)\right. \\
& \left.-\rho_{\text {solid }} \mu_{\text {solid }} L\left(\epsilon_{s, 0}\right)\right) \cdot \exp (-A),
\end{aligned}
$$

$$
\begin{aligned}
I_{\text {liquid-solid }(N>0)}=I_{0} \exp ( & -\rho_{\text {water }} \mu_{\text {water }} L\left(1-\epsilon_{s}\right) \\
& \left.-\rho_{\text {solid }} \mu_{\text {solid }} L\left(\epsilon_{s}\right)\right) \cdot \exp (-A),
\end{aligned}
$$

$$
\varepsilon_{s}=\varepsilon_{s, 0} \frac{\ln \left(I_{\text {liquid-solid }(N>0)} / I_{\text {water only }}\right)}{\ln \left(I_{\text {liquid-solid }(N=0)} / I_{\text {water only }}\right)}
$$

$N_{\text {IS }}$ was also characterized by two conventional techniques for comparison: the visual technique and the pressure gauge technique. For characterizing $N_{\text {IS }}$ with the visual technique, the vessel base was illuminated and the bottom was observed while increasing the impeller speed with a low step size of $10 \mathrm{rpm}$. $N_{\text {JS }}$ was determined according to the Zwietering criteria. For characterizing $N_{\text {JS }}$ by the pressure gauge technique, a calibrated pressure transducer (Lucas Schaevitz Model P3061-20wg) was connected to the vessel bottom. LabView software (National Instruments) was used for data acquisition. Signals were recorded with a sampling time of 1 sec for 5 minutes. The recorded signals were then processed based on the procedure explained by Micale et al. $[10,11]$. In the experiments, various solid loading and impeller clearance conditions were investigated. The effect of the gas flow rate on solid suspension was studied as well. Different scale-up procedures were evaluated to identify which procedure may provide proper scale-up conditions. All experiments were repeated at least three times to ascertain the reproducibility. All experiments have been done in ambient conditions.

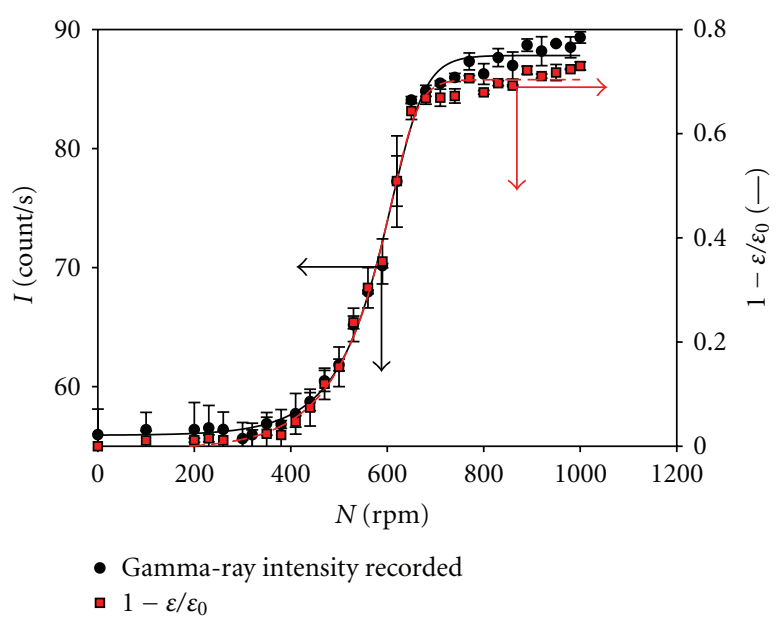

FIGURE 2: Variation of recorded count rate and average solid hold-up by increasing impeller speed at the bottom of the vessel. Impeller: RT, X: $20 \%, d_{p}: 277 \mu \mathrm{m}, C / T: 0.33$.

\section{Results and Discussion}

4.1. Main Features of Solid Suspension. Typical results of the densitometry technique are shown in Figure 2. This figure shows variation of count rate recorded by detector versus impeller speed. At $N=0$ (rpm), when all the solid particles settled on the bottom of the vessel, the recorded intensity by the detector $I_{N=0}$ is constant. By increasing the impeller speed and as solid particles in the scanning region commence motion and are lifted by the liquid, the recorded intensity increases. At higher impeller speeds, when all the solid particles are experiencing random motion and no solid rests on the bottom of the vessel, the recorded intensity is expected to stabilize. In practice, a slight intensity increase can be observed, which is related to the change in solid particle speed and a decrease of the residence time of the solid in the scanning zone.

Solid hold-up can be calculated from recorded count rates by employing (1), (2), (3), and (4). Figure 2 also illustrates the variation of solid hold-up at the bottom of the vessel by increasing impeller speed.

As many researchers have mentioned (e.g., [7]) solid concentration at the bottom of the vessel at just-suspended conditions exhibits a discontinuity. As shown in Figure 2, based on densitometry data, a discontinuity in solid concentration can be noticed at the bottom of the vessel by increasing impeller speed and passing $N_{\text {JS }}$. The starting point of this discontinuity is considered as $N_{\text {JS }}$. $\mathcal{E} / \varepsilon_{0}$ represents the normalized solid volume fraction at the bottom of the vessel. By plotting $1-\varepsilon / \varepsilon_{0}$ vsersus impeller speed the discontinuity in solid concentration at the bottom of the can be identified clearly. As illustrated in Figure 2, for low impeller speed, all solid particles rest on the bottom of the vessel base. Upon increasing impeller speed, a fraction of the solid particles commences lifting and reaches suspension at a certain height. Partial suspensions correspond to the situation where some solids rest on the bottom of the tank. Since the particles are 


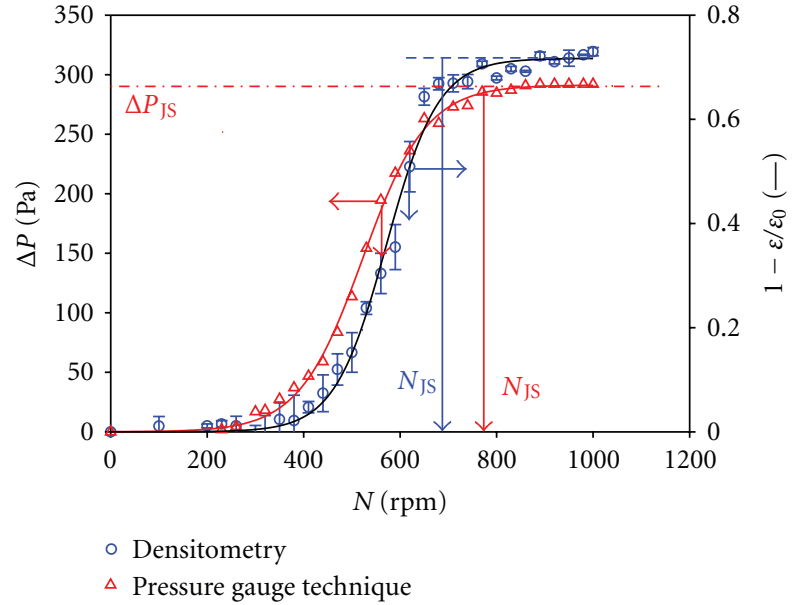

(a)

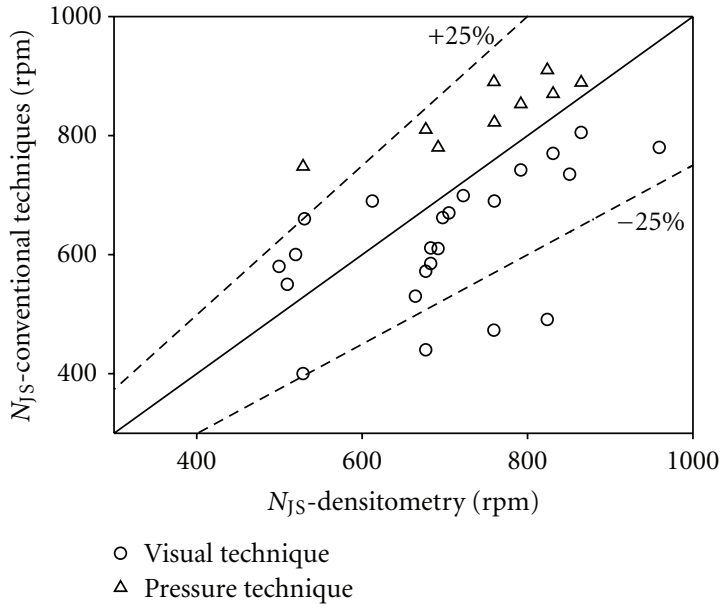

(b)

Figure 3: (a) Comparison of gamma-ray densitometry technique with pressure technique. (b) Comparison of gamma-ray densitometry technique with two conventional methods.

in constant contact with the bottom of the vessel, not all the surface area of particles is available for chemical reaction, mass, or heat transfer.

As the impeller speed is increased, the partially suspended solid yields three distinct zones: a clear liquid layer at the top, a nonsuspended solid layer at the bottom; and a region with a suspended mixture in between. The relative size of the three zones depends on how easily particles can be picked up by the fluid and how efficiently the impeller is agitating the liquid. Increasing impeller speed results in conditions where no particle stagnates at the bottom of the vessel. Although virtually all solid particles are suspended, the system is not yet homogeneous, with a clear interface between the solid-rich and solid-lean regions. By increasing impeller speed beyond the just-suspended condition, the degree of homogeneity increases.

4.2. Comparing Densitometry with the Pressure-Gauge and Visual Observation Techniques. Results of the gamma-ray densitometry technique were compared with those of the two conventional techniques in Figures 3(a) and 3(b).

As illustrated in Figure 3(a), the pressure-gauge technique quite systematically overestimates the just-suspended speed compared to the densitometry technique. This could be related to the fact that the method for eliminating the dynamic head effect is not valid for high solid concentration and for axial flow impellers. As discussed by Micale [10, 11], the dynamic head effect can perturb experimental data significantly. At low solid loading, $N_{\text {JS }}$ determined by the pressure-gauge technique, and the visual method are in good agreement. Differences in $N_{\text {JS }}$ values obtained using the different methods do not exceed 5\%. This difference is well within the range of experimental uncertainty. However, for high solid loading and special cases like an axial flow impeller or low off-bottom impeller clearance, both conventional techniques exhibit larger differences compared to the new method.
4.3. Effect of Impeller Type. The degree of solid suspension in stirred tanks is strongly related to the specific power, pumping capacity and flow pattern. The main source of power dissipation and pumping is the impeller rotation. Researchers have studied a variety of impellers for solid suspension. The choice of a given impeller to achieve maximum solid suspension with minimum power requirement is the key for the technical and economic viability of the process. $N_{\text {JS }}$ is affected significantly by the region of the vessel where the final portion of settled solid particles is brought into suspension. This region varies for different impeller types and vessel geometry.

Three types of impellers have been studied in this paper: Rushton Turbine (RT), Pitched Blade Turbine in downpumping mode (PBT-D), and Concave Blade Turbine (CBT). Axial flow impellers (like PBT-D) are more favorable for liquid-solid mixing processes since they can provide a good quality of solid suspension at lower impeller speed compared to radial flow impellers $[1,37]$, but their instability for being applied in a three-phase system (Gas-liquid-solid) leads us to study RT and CBT as well.

There are two zones on the tank base where recirculation loops are weak: underneath the impeller and at the junction of the tank base and wall. As illustrated in Figure 4(a) for the Rushton turbine, the final settled solids were suspended from underneath the impeller at the centre of the tank. At the same impeller speed, more solids were suspended from other regions compared to the centre. There are many characterization studies regarding the flow pattern of radial and axial flow impellers (e.g., [38-40]). The radial flow generated with radial flow impeller first hits the wall and change direction, moving upward and downward [40, 41]. Downward jet hits bottom of the vessel and is redirected to the center. Thus, the radial flow impeller sweeps particles toward the center of the vessel bottom and lifts them from an annulus around the center of the vessel bottom. As illustrated in Figure 4(a), solid concentration is lower at third scanning 


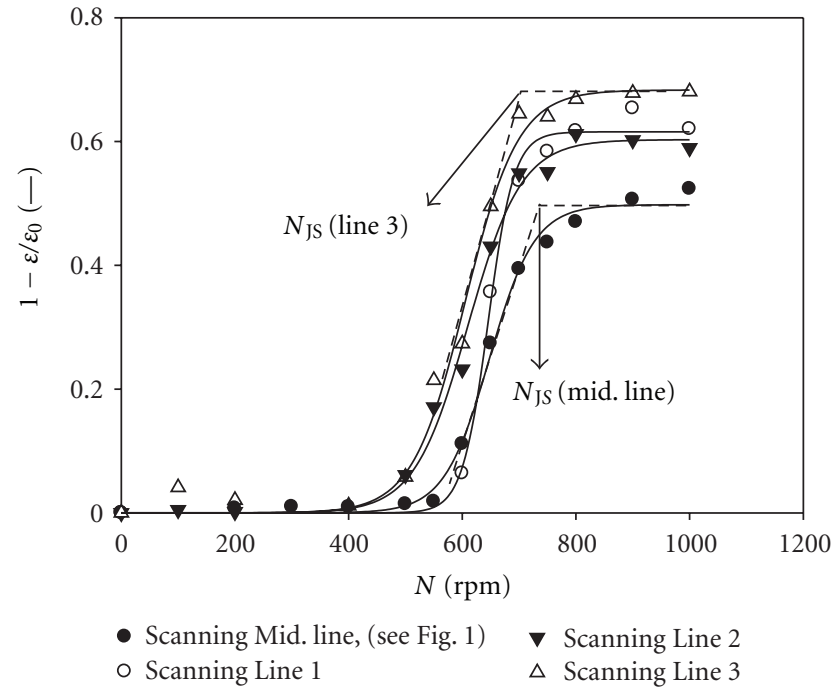

(a)

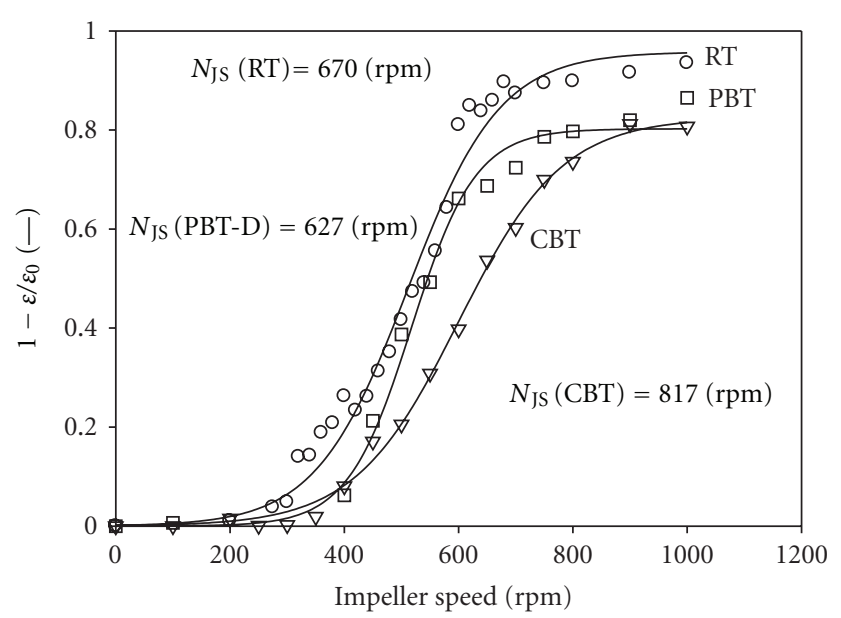

(b)

FIGURE 4: (a) Solid hold-up variation at the bottom of the vessel by increasing impeller speed, for 4 different scanning lines, impeller: RT, $X$ : $30 \%, d p: 277 \mu \mathrm{m}, C / T: 0.33$. (b) Comparison of just-suspended speed for different impellers. $X: 10 \% \mathrm{wt} / \mathrm{wt}, \mathrm{C} / \mathrm{T}: 0.33$.

line, which corresponds to periphery of the vessel, compared to Mid. line.

On the other hand, axial flow impellers tend to suspend solid particles from the periphery of the vessel bottom. The flow generated by axial flow impeller (in down pumping mode) first hits the bottom of the vessel. It is then redirected to the wall and generates liquid wall jet moving upward, which could push solid particle forward and lift them from the periphery of the vessel $[39,42-44]$. Wall jet generated by axial flow impeller at the wall is stronger than the one generated by radial flow impeller. Accordingly, it is more difficult to lift particles from the center than drive them toward the corner. The flow pattern of axial flow impellers facilitates suspension in comparison to radial flow impellers. As shown in Figure 4(b), radial flow impellers require higher impeller speeds for solid suspension compared to axial flow impellers.

4.4. Effect of Solid Loading. The effect of solid concentration on $N_{\text {JS }}$ has also been studied. As shown in Figure 5(a), higher solid loading causes an increase in required $N_{\text {IS. }}$. Upon increasing solid loading, more power is required to suspend large portions of solid. In the plateau region (Figure 5(a)), solid hold-up at the bottom of the vessel is higher at $X=40$ (\% wt $/ \mathrm{wt}$ ) compared to the other case, because the power draw of the impeller is not high enough to disperse the solid. The effect of solid loading on $N_{\text {IS }}$ for the various impellers is summarized in Figure 5(b).

4.5. Effect of Impeller Clearance. The effect of the impeller clearance on the just-suspended speed is illustrated in Figures 6(a) and 6(b). Experimental results show that the clearance has a substantial effect on solid suspension especially for PBT-D. Critical impeller speed for off-bottom suspension increases as the clearance is increased. Based on impeller clearance and type of impeller two radically different flow patterns could be observed: (1) a double-loop shape in which two recirculation loops circulate above and below the impeller and (2) a single-loop shape in which the lower recirculation loop is suppressed. Single-loop flow is typical for axial flow impellers, while double-loop is typical for radial flow impellers. Variation of the flow pattern leads to different solid suspension regimes, which, in turn, affect $N_{\text {JS }}$ as discussed previously. Energy transfer from the impeller to the particles is maximized in configurations where the impeller operates close to the tank base [37]. When the impeller is placed close to the vessel base, the particles trapped at the bottom of the vessel underneath the impeller are initially driven toward the corners. This centre-tocorner motion faces minimal resistance while accumulating sufficient momentum to lift into suspension after sliding to the junction of wall and vessel base. By increasing the impeller off-bottom clearance, the stagnant zone underneath the impeller increases, more solid particles are trapped in that region as less momentum is transferred to the particles. A higher speed (more power) is necessary to force particles to move toward the tank corner from where they become suspended. Figure 6(b) illustrates the variation of solid holdup at the bottom of the vessel for radial flow and axial flow impellers at two different impeller clearances.

The variation of $N_{\mathrm{JS}}$ as a function of impeller clearance is shown in Figure 6(b). Sharma and Shaikh [45] have defined three regions in the $N_{\mathrm{IS}}$ versus impeller clearance plot. In the first region, $N_{\text {IS }}$ remains constant by increasing impeller clearance. This corresponds to the configuration where the impeller is located very close to the vessel base. This phenomenon is related to the local energy dissipated at the tank base, which remains constant when the impeller operates very close to the vessel base [13]. Impellers exhibit a high efficiency for suspending solid particles in this region. 


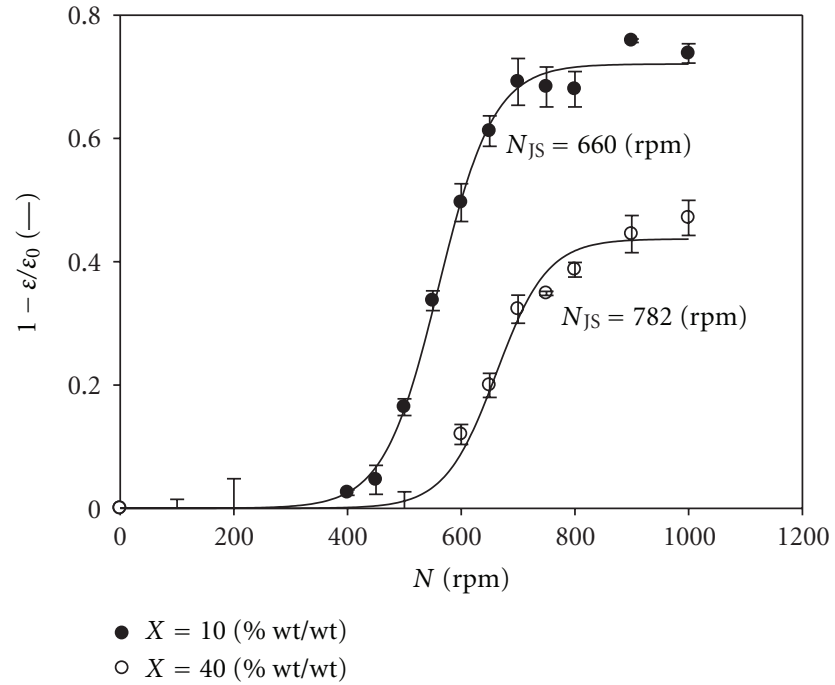

(a)

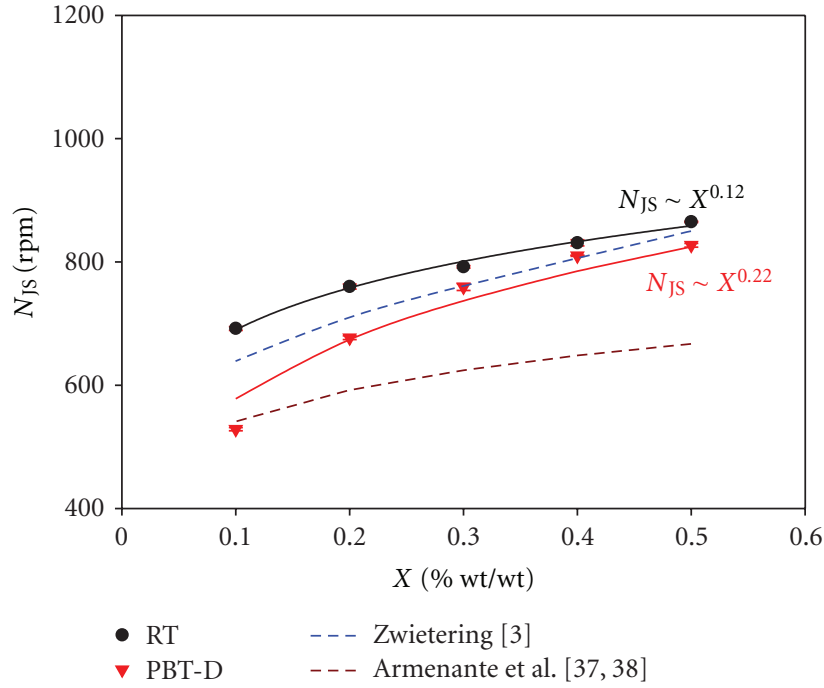

(b)

Figure 5: (a) Variation of solid hold-up at the vessel bottom for low and high solid concentration, impeller: RT, $C / T=0.33$. (b) Variation of $N_{\text {JS }}$ by increasing solid concentration, C/T: 0.33 .

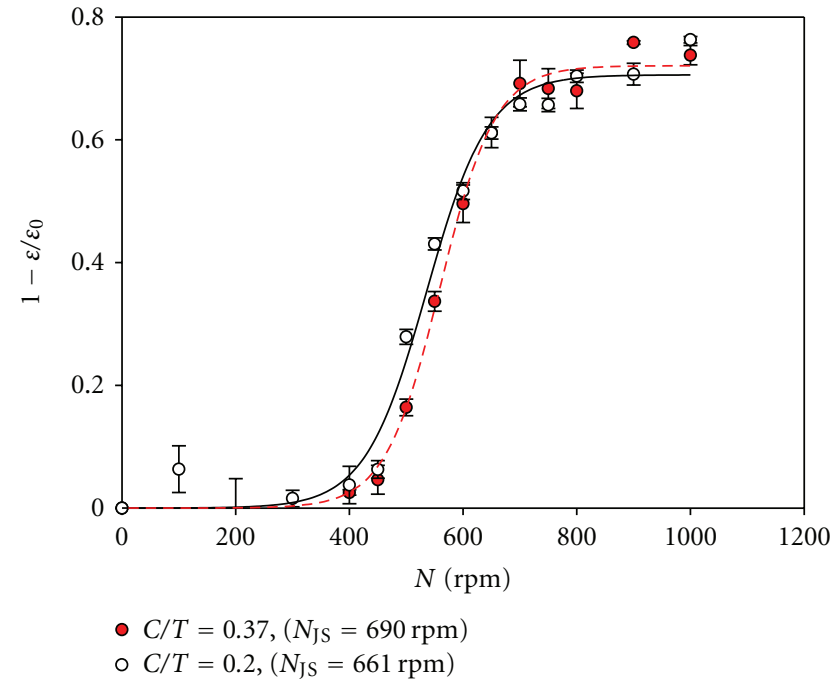

(a)

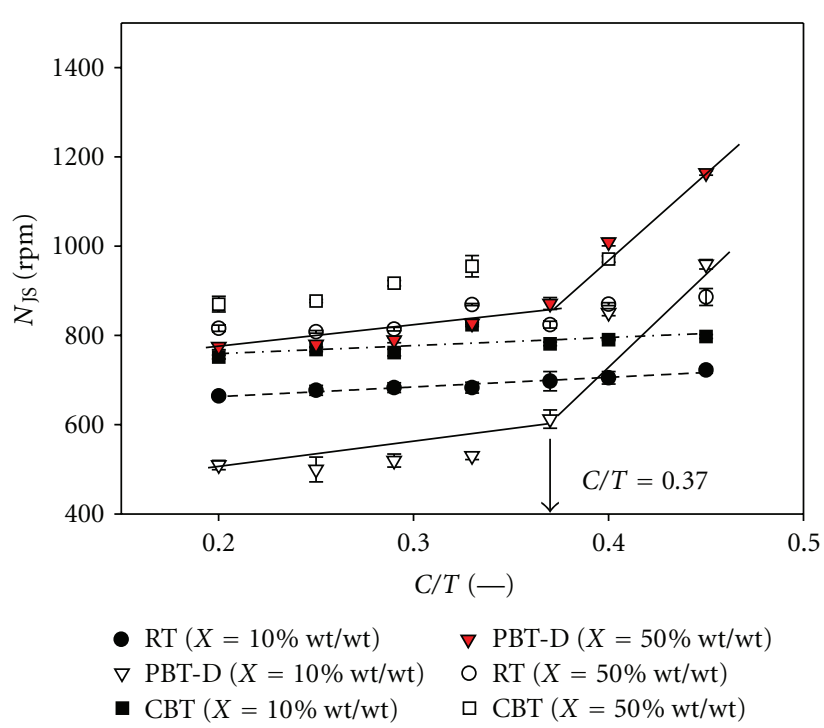

(b)

FIgure 6: (a) Variation of solid hold-up at the vessel bottom for low and high impeller clearance, Impeller: RT. (b) Variation of $N_{\text {JS }}$ by impeller clearance.

According to Sharma and Shaikh [45], this phenomenon can be observed only in conditions where $C / T<0.1$. All impellers with very low clearance $(C / T<0.1)$ behave as axial flow impellers and generate a single-eight loop flow. This low-clearance range is the most efficient condition for the impellers.

The difference between $N_{\text {JS }}$ for different impellers is related to the amount of power dissipated by the impeller in the vessel. As illustrated in Figure 6(b), at impeller clearances higher than $0.2, N_{\text {JS }}$ increases only slightly with increasing clearance. For radial flow impellers, the flow pattern changes from single-loop to double-loop [46] and, as discussed before, this changes the mechanism of solid suspension. At higher impeller clearance, the trend is similar. Impeller efficiency decreases by increasing the impeller clearance and, as a result, $N_{\mathrm{JS}}$ increases.

For the axial flow impeller, a different behavior is observed. At impeller clearances lower than $0.37, N_{\text {JS }}$ increases slightly as the clearance increases. This is observed for the same reason as with radial flow impellers with the added feature that at clearances higher than $0.37, N_{\text {IS }}$ becomes a strong function of the impeller clearance and the slope in 
this region is higher compared to other regions. This increase in $N_{\text {IS }}$ is related to the modification of the flow pattern. At clearances higher than 0.37 , flow lines originating from the impeller hit the wall before they hit the vessel base. After hitting the wall, they slide downward or upward along the wall. This is typical of the double-eight flow pattern generated by radial flow impellers. It means that the axial flow impeller converts to a radial flow impeller. Such an increase cannot be observed for radial flow impellers (RT and CBT). For radial flow impellers $N_{\text {JS }}$ slightly increases since the power available for solid suspension decreases by increasing impeller clearance.

Flow visualization can provide more insight about this phenomenon. As reported in different articles [39, 46, 47], flow transitions occur by increasing impeller clearance for both radial and axial flow impellers. In case of radial flow impeller (RT) transition from double-eight flow patter to single eight happens at $C / T=0.15$ [46]. When the clearance value is less than or equal to $0.15 \mathrm{~T}$, the strong inclination of impeller stream can be utilized to promote solid suspension from bottom of the vessel. With clearance higher than $0.15 \mathrm{~T}$ a double eight flow pattern is produced (e.g., [41]) and it was shown that an annular wall jet exists at the wall of the tank. By increasing the impeller clearance, downward wall jet weakens, which explains the higher impeller speed required for off-bottom suspension.

For axial flow impeller, at critical value of impeller clearance, impeller's discharge flow will impinge on the vessel wall rather than the base, which leads to two flow loops in the vessel. The primary flow loop moves upward the wall. The secondary flow loop is characterized by low-velocity, radially inward flow at the base of the vessel, which returns to the impeller via up-flow at the center of the vessel. This flow pattern that is known as reveres flow is not well suited for solid suspension. Different values have been reported for clearance at which axial impeller undergoes a distinct transition. It is strongly affected by type of impeller, $D / T$ ratio, and impeller blade angle $[39,47]$. The critical value for PBT-D reported as $C / T=0.37$ (Figure 6(b)) in this work.

4.6. Comparing with Correlations. Different correlations have been proposed for predicting $N_{\text {JS }}$ (with general format of (5)). However, no correlations with global agreement have been presented so far. As illustrated in Figure 7, the agreement between the prediction and experimental data is not good, which means there is no equation with global validity

$$
N_{\text {JS }}=S v^{\alpha}\left[\frac{g_{c}\left(\rho_{s-} \rho_{l}\right)}{\rho_{l}}\right]^{\beta} d_{p}^{\gamma} D^{\delta} X^{\theta} .
$$

The subjectivity of conventional experimental techniques causes significant differences between predicted values for the same system. Most of the studies resulted in modifications of model parameters in the Zwietering correlation. Values determined for the model parameters $(\alpha, \beta, \gamma, \delta$, and $\theta$ in (5)) in different studies are almost similar to each other, but in Figure 7 high differences between measured and predicted values can be seen. Therefore, it can be concluded that

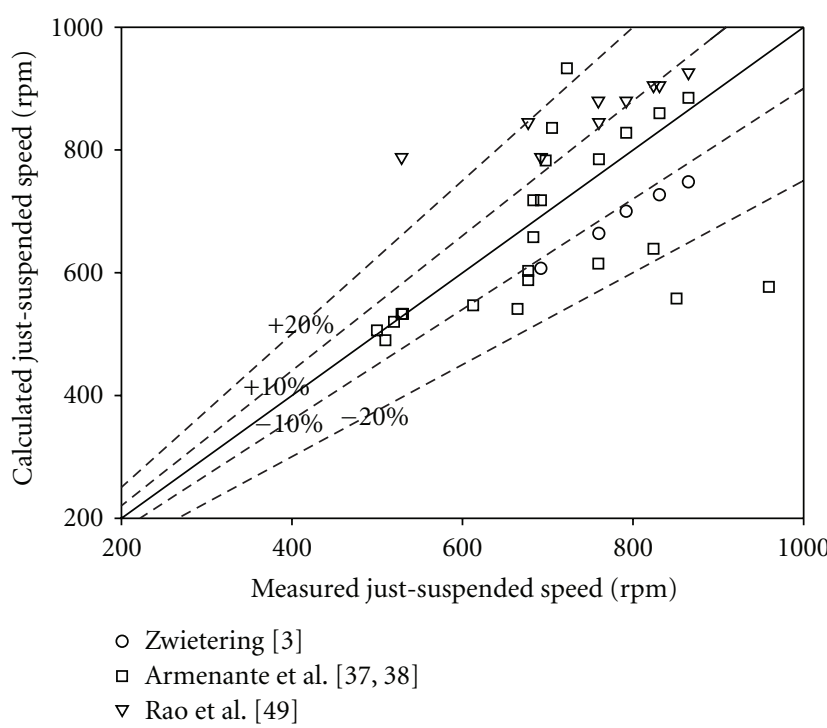

FIGURE 7: Comparing measured values for just-suspended speed by densitometry technique and predicted ones with different models $[3,37,49]$.

TABLE 4: Values for $a$ and $b$ parameters in equation 3 for different impellers.

\begin{tabular}{lcc}
\hline Impeller & $a$ & $b$ \\
\hline RT $(0.1<C / T)$ & 4.7 & 1.1 \\
PBT-D $(0.1<C / T<0.35)$ & 3.47 & 1.35 \\
CBT $(0.1<C / T)$ & 5.4 & 0.98 \\
\hline
\end{tabular}

the difference between measured values and predicted ones can be related to variations of the dimensionless number $S$ in Zwietering's correlation, which is a function of impeller size, type, and clearance. The value of $S$ changes linearly for radial impellers with increasing impeller clearance. For axial impellers, however, $S$ is significantly affected by impeller clearance beyond the critical point [37]. As a result, the Zwietering correlation can be modified as follows:

$$
N_{\mathrm{JS}}=\left(a+b \frac{C}{T}\right) v^{\alpha}\left[\frac{g_{c}\left(\rho_{s-} \rho_{l}\right)}{\rho_{l}}\right]^{\beta} d_{p}^{\gamma} D^{\delta} X^{\theta},
$$

where $\theta=0.12$ and 0.22 for RT and PBT-D, respectively, $\delta=-0.85, \gamma=0.2, \beta=0.45, \alpha=0.1$. Values for $a$ and $b$ for different impellers are given in Table 4 .

In Figure 7, comparison between predicted values by new model and previous published models $[3,37,48]$ are illustrated.

4.7. Effect of Scale. The effect of scale on $N_{\text {JS }}$ was also evaluated by the gamma-ray densitometry technique. For this purpose, experiments were repeated in a larger vessel $(T=$ $0.4 \mathrm{~m}$ ) at different solid concentrations for PBT-D and RT. Results are reported in Figure 8. Different scale-up methods

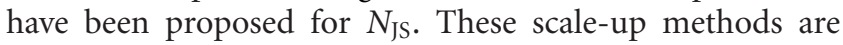
divided into two categories. The first category includes two common approaches used by engineers to scale-up stirred 


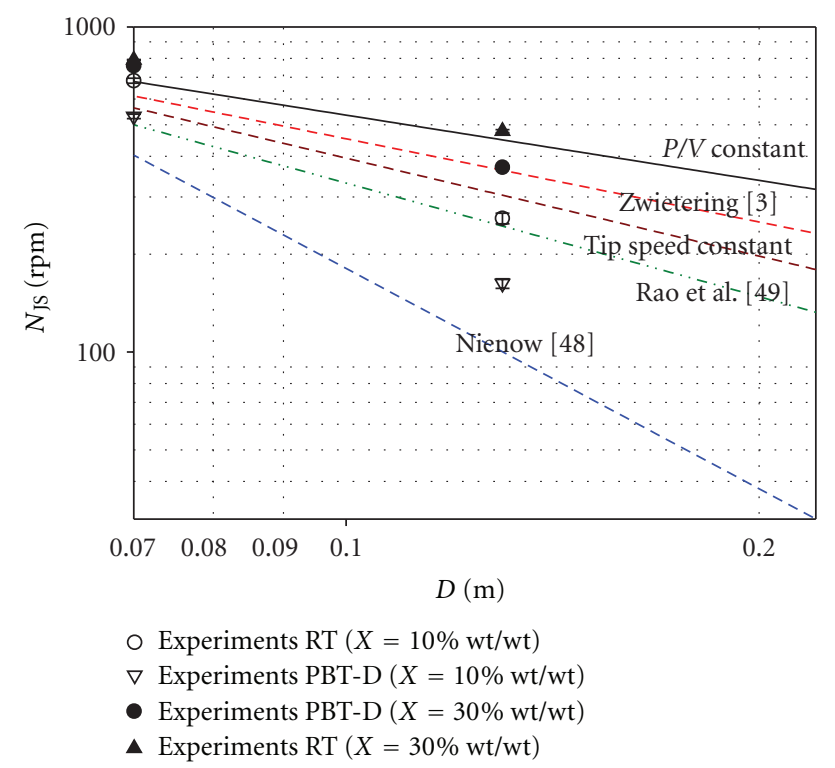

FIGURE 8: Variation of $N_{\text {JS }}$ by increasing scale and comparison with different scale-up procedures [3, 48, 49].

tanks, that is, constant specific power $(P / V)$ and constant tip speed. The second category includes the scale-up procedure developed based on empirical studies or theoretical concepts. As it was shown in Figure 8, applying different scale-up rules leads to significant differences in predicting $N_{\text {JS }}$ for larger scale. The reader should note that even a small difference in the exponent of $D$ can have large effect on power consumption when $N_{\text {JS }}$ is scaled-up. At high solid loading, for RT, constant $P / V$ seems a promising method but for PBT-D, at same solid loading, tip speed constant may provide better prediction. At low solid loading, the criterion proposed by Nienow [19] is more accurate. Clearly, there is no scale-up procedure with global validity, and appropriate operating condition at large scale, for any mixing system, should be determined independently.

4.8. Application of the Gamma-Ray Densitometry Technique in a Three-Phase System. Solid suspension is also a key factor in three-phase (GLS) stirred tanks. In a three-phase system, the presence of gas makes the solid suspension a more complex phenomenon. It is common knowledge [1] that the presence of gas decreases the ability of the impeller for solid suspension due to (1) decreasing the power dissipation in the system and (2) affecting the flow pattern of the liquid phase resulting in reducing the liquid-solid slip velocity. Reduction of slip velocity decreases the interphase forces (drag and lift), which are responsible for solid pickup from the vessel base. As illustrated in Figure 9 by increasing the gas flow rate, a higher impeller speed is required to achieve just offbottom suspension. The differences between literature data and densitometry technique are considerable.

The use of the visual technique in the presence of gas is more difficult. Gas flow (at very low values) could help the suspension of solid particles, but as reported in the

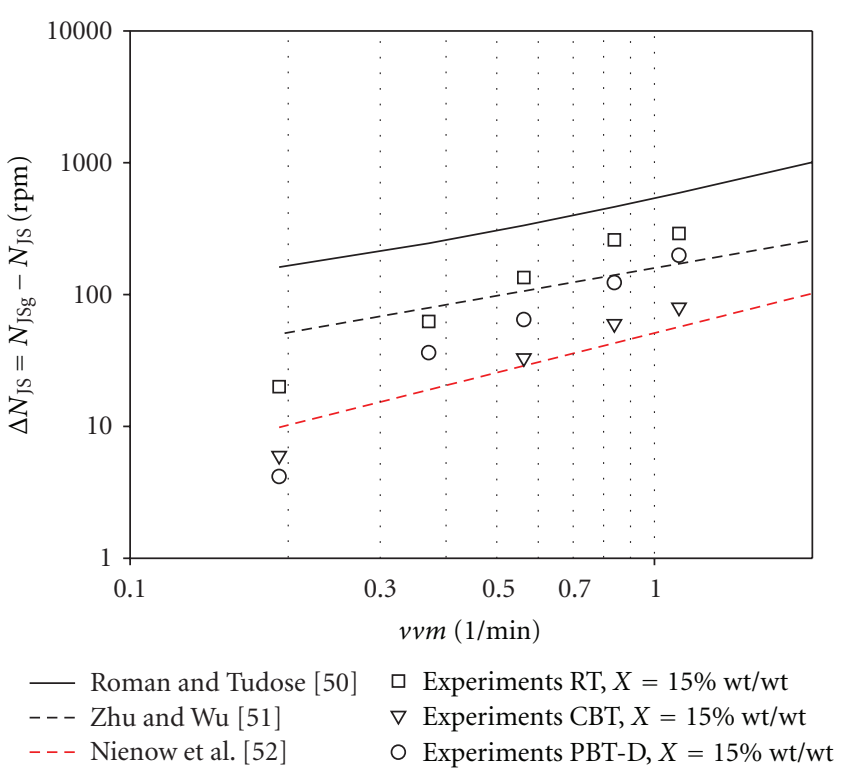

FIGURE 9: Variation of $\Delta N_{\text {JS }}$ in gas-liquid-solid system by increasing gas flow rate: experimental data compared with correlations [5052].

illustrated in Figure 9, increasing the gas flow rate directly affects the impeller performance. Accordingly, $\Delta N_{\text {JS }}\left(=N_{\text {JSg }}-\right.$ $N_{\text {JS }}$ ) increases by increasing the gas flow rate. Radial and axial flow impellers show different behavior in the GLS system. As can be seen in Figure 9, performance of CBT is less affected by presence of gas compared to two other impellers.

4.9. Theoretical Prediction of $N_{\text {JS }}$. The empirical correlations for predicting $N_{\text {JS }}$, which typically take the form of (6), do not facilitate the understanding of the particle suspension mechanism, and theoretical models may provide more insight about the suspension mechanism. The method considered here is based on a force balance acting on a single particle resting at the bottom of the vessel. If we consider a solid particle resting at the bottom of the vessel in liquid, which is under turbulent agitation, by increasing impeller speed particles may start to move by rolling, sliding or lifting. Once particles have lifted up from bottom of the vessel they can be carried away due to the sedimentation-dispersion mechanism. Different forces may act on a single spherical particle when it moves in turbulent media [53]. Based on what is reported in the literatures for solid motion in a stirred tank (e.g., [53]), also by considering an analogy with particle minimum pickup velocity in pipes (e.g., $[54,55])$, for the particle resting at the bottom of the vessel and at the moment of dislodgment, the force balance on single particle can be written as

$$
\frac{1}{2} A_{p} \rho_{l} C_{D} v_{l-\mathrm{JS}}^{2}-g V_{p}\left(\rho_{S}-\rho_{l}\right)-\rho_{S l} g H A_{p}=0,
$$

which on solving for velocity yields

$$
v_{l \text {-JS }}=\sqrt{\frac{4 g d p\left(\rho_{s}-\rho_{l}\right)}{3 \rho_{l} C_{D}}+\frac{\rho_{l s} H g}{\rho_{l} C_{D}}} .
$$


$v_{l-j s}$ is the minimum velocity of fluid required to initiate the just-suspended condition of solid particles. Equation (7) assumes complete "wet-ability" of solids by the liquid and also assumes no slip between particles and fluid. It also assumes spherical particles. Equation (8) describes the minimum liquid velocity required at the bottom of the vessel for pick-up particles at conditions close to just-suspended speed, and it is sensitive to liquid and solid physical properties ( $d p$, $\rho_{s}, \rho_{l}, \nu$ ) and solid concentration (through slurry density and $\left.C_{D}\right)$. It is necessary to find an appropriate approach for relating the impeller speed to this minimum liquid velocity. If such a relation exists, it would be possible to determine $N_{\text {JS }}$ theoretically for any mixing system by knowing physical properties of the liquid and solid phase and solid loading. In light of the lack of accurate data concerning local liquid velocity at the bottom of the vessel for dense liquid-solid systems [56, 57], local liquid velocity could be determined from circulation time in a single-phase stirred tank. McManamey [58] proposed that the time required for the liquid to circulate once through the flow path should be equal to the maximum length of the circulation path divided by the average liquid velocity in the circulation path $(t=$ (liquid circulation path)/(liquid velocity)). The liquid circulation path can calculated from the geometry of the vessel and impeller type. For a PBT-D impeller the liquid circulation path is $2 H+T / 2$ [59] and for an RT impeller it is $3 T-2 C$ [30]. Accordingly, we will have $t_{c}=(3 T-2 c) / v_{l}$ for RT and $t_{c}=3 T / v_{l}$ for PBT-D. The circulation time can be expressed as a function of impeller speed, liquid properties, and tank and impeller geometry [60]. In stirred tanks, mixing time can be assumed to be some multiple of the circulation time $[16,61,62]$. In this case, accurate correlations for predicting mixing time in dense liquid-solid mixing systems may help to predict the correct $N_{\text {IS }}$ values. However, by applying this approach, the calculated $N_{\mathrm{JS}}$ values were highly different compared to current experimental results. This leads to the conclusion that the minimum liquid velocity at the bottom of the vessel required for off-bottom suspension is much lower than the average circulation velocity.

Van der Molen and Van Maanen [63], based on investigations with a laser-Doppler velocimeter, have found that the average velocity at the wall of the stirred tank could be calculated as $v_{l}=C_{1} U_{\text {tip }}(D / T)^{7 / 6}$. At just-suspended conditions, we can rewrite this equation as

$$
\begin{aligned}
& v_{l-\mathrm{SS}}=C_{1} U_{\text {tip-JS }}\left(\frac{D}{T}\right)^{7 / 6} \text { or } \\
& v_{l-\mathrm{JS}}=C_{1} N_{\mathrm{JS}} \pi D\left(\frac{D}{T}\right)^{7 / 6} .
\end{aligned}
$$

For the system used in this study, minimum liquid velocity at the bottom of the vessel at just-suspended condition $\left(v_{l-\mathrm{JS}}\right)$ was calculated from (8). Calculated $v_{l-\mathrm{SS}}$ and experimental values for $N_{\text {IS }}$ were replaced in equation (9) and $C_{1}$ defined for RT and PBT-D. For RT, at constant solid loading, $C_{1}$ increases very slightly by increasing impeller clearance (average value $=0.05$ ); however, it shows linearly increases by increasing solid loading (slope: 0.18). For PBT-D, $C_{1}$ increases linearly by increasing solid loading

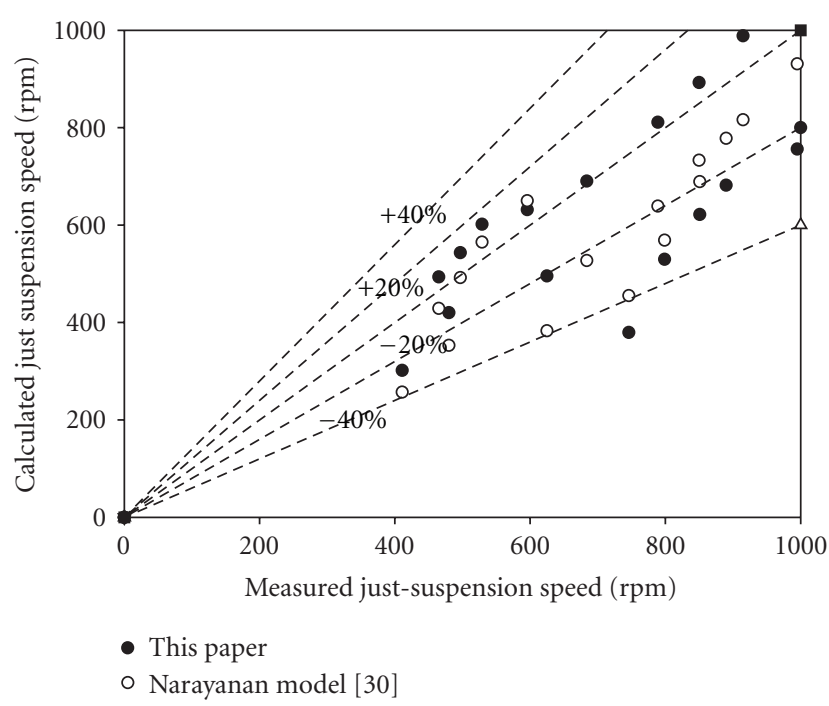

FIGURE 10: Comparing $N_{\text {JS }}$ calculated from semitheoretical model proposed in this work with model and experimental data proposed by Narayanan et al. [30].

(slope: 0.13). It is constant for low impeller clearances that is, $C / T<0.37\left(C_{1}=0.07\right)$. Results of the theoretical prediction of $N_{\text {IS }}$ using the current method were compared with experimental data reported by Narayanan [33] and the model they have proposed in Figure 10. Narayanan et al. [33] have done experiments in systems where clearance is 0.5 and solid loading varies between $5 \%$ and $20 \%$. Both models exhibit almost same accuracy. The combination of (8) and (9) provides a very simple and semitheoretical approach for predicting just-suspended impeller speed. The uncertainty of predicted $N_{\text {JS }}$ could be decreased by modifying (9) based on local measurement of the liquid velocity at the bottom of the vessel $[51,52]$.

\section{Summary and Conclusions}

To overcome limitations of conventional techniques for characterizing just-suspended speed in liquid-solid mixing systems, a novel technique was developed based on gammaray densitometry. This technique represents an original approach and a convenient means of measuring justsuspended speed in systems where visual observation is not possible. Even in the systems where other methods are applicable, the densitometry technique can provide more accurate measurement. It was clearly observed that, based on impeller clearance, axial and radial impellers operate differently. All impellers are efficient at low clearance. However, there exists a critical clearance where the flow pattern of the axial flow impeller changes. It was also shown that correlations for predicting $N_{\text {IS }}$ do not have universal validity. Correlation for predicting $N_{\text {IS }}$ was modified based on gamma-ray densitometry results. Finally, a theoretical approach was proposed based on the analogy between solid suspension in stirred tanks and the incipient movement of solid particles in pipes. This model shows good agreement 
with experimental data collected from the literature. However, model accuracy could be improved by local solid-liquid characterization close to the bottom of the vessel.

\section{Nomenclatures}

$a: \quad$ Constant of equation (6)(-)

A: $\quad$ Surface area $\left(\mathrm{m}^{2}\right)$, attenuation of vessel, and environment $(-)$

$A_{p}:$ Particle surface area $\left(\mathrm{m}^{2}\right)$

$b: \quad$ Constant of equation (6) (-)

$C: \quad$ Impeller clearance $(\mathrm{m})$

$C_{D}:$ Drag coefficient $(-)$

$D: \quad$ Impeller diameter $(\mathrm{m})$

$d p:$ Average particle diameter $(\mathrm{m})$

$g: \quad$ Gravity acceleration $\left(\mathrm{m} / \mathrm{s}^{2}\right)$

$H$ : Liquid height $(\mathrm{m})$

I: $\quad$ Count rate (count/sec)

$P: \quad$ Pressure $(\mathrm{Pa})$

$\Delta P: \quad$ Pressure difference in pressure gauge technique, $P_{N>0}-P_{N=0},(\mathrm{~Pa})$

$L: \quad$ Scanning length $(\mathrm{m})$

$N$ : Impeller speed $(1 / \mathrm{sec})$

$S: \quad$ Zwietering correlation constant (-)

$t_{c}: \quad$ Circulation time (sec)

$v_{l-\text {-sS }}$ : Liquid velocity at the bottom of the vessel at just-suspended condition $(\mathrm{m} / \mathrm{s})$

$v p$ : Particle volume $\left(\mathrm{m}^{3}\right)$

$v v m$ : Volume of gas per unit volume of liquid per minute $(1 / \mathrm{min})$

$W: \quad$ Blade width $(\mathrm{m})$

$X$ : Solid loading $M s / M t \times 100$ (\% wt/wt-).

Greek Letters

$\alpha, \beta, \gamma, \delta, \theta$ : Constants of equation(6)

$\Delta N_{\text {JS }}: \quad N_{\text {JSg }}-N_{\text {IS }}(\mathrm{rpm})$

$\rho: \quad$ Density $\left(\mathrm{kg} / \mathrm{m}^{3}\right)$

$\mu: \quad$ Mass attenuation coefficient $\left(\mathrm{kg} / \mathrm{m}^{2}\right)$

$\varepsilon: \quad \quad$ Solid hold-up or volume fraction $(-)$

$v$ : Liquid dynamic viscosity.

\section{Subscripts}

$i$ : Representation of scanningsection

imp: Impeller

js: Just-suspended, liquid-solid system

jsg: Just-suspended, gaz-liquid-solid

$l: \quad$ Liquid

s: $\quad$ Solid

ls: $\quad$ Slurry

0: $\quad$ Initial condition $(N=0 \mathrm{rpm})$.

\section{Acknowledgments}

The authors wish to acknowledge the support provided by the Chemical Engineering Department of Ecole
Polytechnique, National Science and Engineering Research Council of Canada (NSERC), and COREM. Thanks are also due to Dr. Kennedy and Mr. Jean St-pier for providing the radioactive isotopes.

\section{References}

[1] V. A. Atieme-Obeng, W. R. Penney, and P. Armenante, "Solidliquid mixing," in Handbook of Industrial Mixing, Science and Practice, E. L. Paul, V. A. Atiemo-Obeng, and S. M. Kresta, Eds., pp. 543-584, John Wiley \& Sons, Hoboken, NJ, USA, 2004.

[2] M. Bohnet and G. Niesmak, "Distribution of solid in stirred suspension," German Chemical Engineering, vol. 3, no. 1, pp. $57-65,1980$.

[3] T. N. Zwietering, "Suspending of solid particles in liquid by agitators," Chemical Engineering Science, vol. 8, no. 3-4, pp. 244-253, 1958.

[4] G. R. Kasat and A. B. Pandit, "Review on mixing characteristics in solid-liquid and solid-liquid-gas reactor vessels," Canadian Journal of Chemical Engineering, vol. 83, no. 4, pp. 618-643, 2005.

[5] A. Mersmann, F. Werner, S. Maurer, and K. Bartosch, "Theoretical prediction of the minimum stirrer speed in mechanically agitated suspensions," Chemical Engineering and Processing, vol. 37, no. 6, pp. 503-510, 1998.

[6] V. B. Rewatkar, K. S. M. S. Raghava Rao, and J. B. Joshi, "Critical impeller speed for solid suspension in mechanically agitated three-phase reactors. 1. Experimental part," Industrial and Engineering Chemistry Research, vol. 30, no. 8, pp. 17701784, 1991.

[7] L. Musil, J. Vlk, and H. Jiroudková, "Suspending solid particles in an agitated tank with axial-type impellers," Chemical Engineering Science, vol. 39, no. 4, pp. 621-628, 1984.

[8] C. M. Chapman, A. W. Nienow, M. Cooke, and J. C. Middleton, "Particle-gas-liquid mixing in stirred vesselspart I: particle-liquid mixing," Chemical Engineering Research and Design, vol. 61, pp. 71-81, 1983.

[9] C. Buurman, G. Resoort, and A. Plaschkes, "Scaling-up rules for solids suspension in stirred vessels," in Proceedings of the 5th European Conference on Mixing, 1985.

[10] G. Micale, V. Carrara, F. Grisafi, and A. Brucato, "Solids suspension in three-phase stirred tanks," Chemical Engineering Research and Design, vol. 78, no. 3, pp. 319-326, 2000.

[11] G. Micale, F. Grisafi, and A. Brucato, "Assessment of particle suspension conditions in stirred vessels by means of pressure gauge technique," Chemical Engineering Research and Design, vol. 80, no. 8, pp. 893-902, 2002.

[12] R. Jafari, P. A. Tanguy, and J. Chaouki, "Comprehensive review of just suspended speed in liquid-solid and gas-liquid-solid stirred tank reactors," Chemical Engineering Journal, vol. 10, no. 1, 2012.

[13] G. Baldi, R. Conti, and E. Alaria, "Complete suspension of particles in mechanically agitated vessels," Chemical Engineering Science, vol. 33, no. 1, pp. 21-25, 1978.

[14] P. Ayazi Shamlou and A. Zolfagharian, "Incipient solid motion in liquids in mechanically agitated vessels," in Proceedings of the 3rd Fluid Mixing Conference, pp. 195-208, September 1987.

[15] O. Molerus and W. Latzel, "Suspension of solid particles in agitated vessels-II. Archimedes numbers > 40, reliable prediction of minimum stirrer angular velocities," Chemical Engineering Science, vol. 42, no. 6, pp. 1431-1437, 1987. 
[16] K. Saravanan, A. W. Patwardhan, and J. B. Joshi, "Critical impeller speed for solid suspension in gas inducing type mechanically agitated contactors," Canadian Journal of Chemical Engineering, vol. 75, no. 4, pp. 664-676, 1997.

[17] S. Hosseini, D. Patel, F. Ein-Mozaffari, and M. Mehrvar, "Study of solid-liquid mixing in agitated tanks through computational fluid dynamics modeling," Industrial and Engineering Chemistry Research, vol. 49, no. 9, pp. 4426-4435, 2010.

[18] N. C. S. Kee and R. B. H. Tan, "CFD simulation of solids suspension in mixing vessels," Canadian Journal of Chemical Engineering, vol. 80, no. 4, pp. 721-726, 2002.

[19] B. N. Murthy, R. S. Ghadge, and J. B. Joshi, "CFD simulations of gas-liquid-solid stirred reactor: prediction of critical impeller speed for solid suspension," Chemical Engineering Science, vol. 62, no. 24, pp. 7184-7195, 2007.

[20] A. Ochieng and A. E. Lewis, "CFD simulation of solids offbottom suspension and cloud height," Hydrometallurgy, vol. 82, no. 1-2, pp. 1-12, 2006.

[21] R. Panneerselvam, S. Savithri, and G. D. Surender, "Computational fluid dynamics simulation of solid suspension in a gasliquid-solid mechanically agitated contactor," Industrial and Engineering Chemistry Research, vol. 48, no. 3, pp. 1608-1620, 2009.

[22] D. F. Fletcher and G. J. Brown, "Numerical simulation of solid suspension via mechanical agitation: effect of the modelling approach, turbulence model and hindered settling drag law," International Journal of Computational Fluid Dynamics, vol. 23 , no. 2, pp. 173-187, 2009.

[23] J. Lea, "Suspension mixing tank-design heuristic," Chemical Product and Process Modeling, vol. 4, no. 1, article 17, 2009.

[24] F. Wang, Z. Mao, and X. Shen, "Numerical study of solidliquid two-phase flow in stirred tanks with Rushton impeller (II) Prediction of critical impeller speed," Chinese Journal of Chemical Engineering, vol. 12, no. 5, pp. 610-614, 2004.

[25] A. Ochieng and M. S. Onyango, "CFD simulation of solids suspension in stirred tanks: review," Hemijska Industrija, vol. 64, no. 5, pp. 365-374, 2010.

[26] H. Bashiri, J. Chaouki, F. Bertrand, and M. Heniche, "Cfdbased compartmental modelling of stirred tank reactors," in Proceedings of the GLS10, Braga, Portugal, 2011.

[27] J. Chaouki, F. Larachi, and M. P. Duduković, "Noninvasive tomographic and velocimetric monitoring of multiphase flows," Industrial and Engineering Chemistry Research, vol. 36, no. 11, pp. 4476-4503, 1997.

[28] B. Esmaeili, J. Chaouki, and C. Dubois, "An evaluation of the solid hold-up distribution in a fluidized bed of nanoparticles using radioactive densitometry and fibre optics," Canadian Journal of Chemical Engineering, vol. 86, no. 3, pp. 543-552, 2008.

[29] V. Kolar, "Suspensing solid particles in liquids by menas of mechanical agitation," Collection of Czechoslovak Chemcial Communications, vol. 26, pp. 613-627, 1961.

[30] S. Narayanan, V. K. Bhatia, D. K. Guha, and M. N. Rao, "Suspension of solids by mechanical agitation," Chemical Engineering Science, vol. 24, no. 2, pp. 223-230, 1969.

[31] D. Subbarao and V. K. Taneja, "Three phase suspensions in agitated vessels," in Proceedings of the 3rd European Conference on Mixing, York, UK, 1979.

[32] P. Ditl and F. Rieger, "Suspension of solids particle-relative velocity of particles in turbulent mixing," in Proceedings of the 5th European Confon Mixing, Wurzburg, West Germany, 1985.

[33] L. Musil and J. Vlk, "Suspending solid particles in an agitated conical-bottom tank," Chemical Engineering Science, vol. 33, no. 8, pp. 1123-1131, 1978.
[34] P. Ditl and F. Rieger, "Suspension of solid particles-letter to the editors," Chemical Engineering Science, vol. 35, pp. 764$765,1980$.

[35] O. Molerus and W. Latzel, "Suspension of solid particles in agitated vessels-I. Archimedes numbers $\lesssim 40$," Chemical Engineering Science, vol. 42, no. 6, pp. 1423-1430, 1987.

[36] K. Wichterle, "Conditions for suspension of solids in agitated vessels," Chemical Engineering Science, vol. 43, no. 3, pp. 467471, 1988.

[37] P. M. Armenante and E. U. Nagamine, "Effect of low offbottom impeller clearance on the minimum agitation speed for complete suspension of solids in stirred tanks," Chemical Engineering Science, vol. 53, no. 9, pp. 1757-1775, 1998.

[38] P. M. Armenante and C. C. Chou, "Velocity profiles in a baffled vessel with single or double pitched-blade turbines," AIChE Journal, vol. 42, no. 1, pp. 42-54, 1996.

[39] S. M. Kresta and P. E. Wood, "Mean flow field produced by a $45^{\circ}$ pitched blade turbine: changes in the circulation pattern due to off bottom clearance," Canadian Journal of Chemical Engineering, vol. 71, no. 1, pp. 42-53, 1993.

[40] T. Kumaresan and J. B. Joshi, "Effect of impeller design on the flow pattern and mixing in stirred tanks," Chemical Engineering Journal, vol. 115, no. 3, pp. 173-193, 2006.

[41] S. M. Kresta, K. J. Bittorf, and D. J. Wilson, "Internal annular wall jets: radial flow in a stirred tank," AIChE Journal, vol. 47, no. 11, pp. 2390-2401, 2001.

[42] Z. Jaworski, A. W. Nienow, and K. N. Dyster, "An LDA study of the turbulent flow field in a baffled vessel agitated by an axial, down-pumping hydrofoil impeller," Canadian Journal of Chemical Engineering, vol. 74, no. 1, pp. 3-15, 1996.

[43] M. Schäfer, M. Yianneskis, P. Wächter, and F. Durst, "Trailing vortices around a $45^{\circ}$ pitched-blade impeller," AIChE Journal, vol. 44, no. 6, pp. 1233-1246, 1998.

[44] G. Zhou and S. M. Kresta, "Impact of tank geometry on the maximum turbulence energy dissipation rate for impellers," AIChE Journal, vol. 42, no. 9, pp. 2476-2490, 1996.

[45] R. N. Sharma and A. A. Shaikh, "Solids suspension in stirred tanks with pitched blade turbines," Chemical Engineering Science, vol. 58, no. 10, pp. 2123-2140, 2003.

[46] G. Montante, K. C. Lee, A. Brucato, and M. Yianneskis, "An experimental study of double-to-single-loop transition in stirred vessels," Canadian Journal of Chemical Engineering, vol. 77, no. 4, pp. 649-659, 1999.

[47] K. J. Myers, A. Bakker, and R. R. Corpstein, "The effect of flow reversal on solids suspension in agitated vessels," Canadian Journal of Chemical Engineering, vol. 74, no. 6, pp. 1028-1033, 1996.

[48] A. W. Nienow, "Suspension of solid particles in turbine agitated baffled vessels," Chemical Engineering Science, vol. 23, no. 12, pp. 1453-1459, 1968.

[49] K. S. M. S. Raghava Rao, V. B. Rewatkar, and J. B. Joshi, "Critical impeller speed for solid suspension in mechanically agitated contactors," AIChE Journal, vol. 34, no. 8, pp. 13321340, 1988.

[50] R. V. Roman and R. Z. Tudose, "Studies on transfer processes in mixing vessels: effect of gas on solid- liquid hydrodynamics using modified Rushton turbine agitators," Bioprocess Engineering, vol. 17, no. 1, pp. 55-60, 1997.

[51] Y. Zhu and J. Wu, "Critical impeller speed for suspending solids in aerated agitation tanks," Canadian Journal of Chemical Engineering, vol. 80, no. 4, pp. 682-687, 2002.

[52] A. W. Nienow, M. Konno, and W. Bujalski, "Studies on threephase mixing: a review and recent results," in Proceedings of the 
5th European Conference on Mixing, Wurzburg, West Germany, 1985.

[53] J. J. Derksen, "Numerical simulation of solids suspension in a stirred tank," AIChE Journal, vol. 49, no. 11, pp. 2700-2714, 2003.

[54] E. Rabinovich and H. Kalman, "Incipient motion of individual particles in horizontal particle-fluid systems-B. Theoretical analysis," Powder Technology, vol. 192, no. 3, pp. 326-338, 2009.

[55] P. Stevenson, R. B. Thorpe, and J. F. Davidson, "Incipient motion of a small particle in the viscous boundary layer at a pipe wall," Chemical Engineering Science, vol. 57, no. 21, pp. 4505-4520, 2002.

[56] R. Fishwick, M. Winterbottom, D. Parker, X. Fan, and H. Stitt, "The use of positron emission particle tracking in the study of multiphase stirred tank reactor hydrodynamics," Canadian Journal of Chemical Engineering, vol. 83, no. 1, pp. 97-103, 2005.

[57] D. Guha, P. A. Ramachandran, and M. P. Dudukovic, "Flow field of suspended solids in a stirred tank reactor by Lagrangian tracking," Chemical Engineering Science, vol. 62, no. 22, pp. 6143-6154, 2007.

[58] W. J. McManamey, "Circulation model for batch mixing in agitated, baffled vessels," Transactions of the Institution of Chemical Engineers, vol. 58, no. 4, pp. 271-276, 1980.

[59] J. B. Joshi, A. B. Pandit, and M. M. Sharma, "Mechanically agitated gas-liquid reactors," Chemical Engineering Science, vol. 37, no. 6, pp. 813-844, 1982.

[60] D. B. Holmes, R. M. Voncken, and J. A. Dekker, "Fluid flow in turbine-stirred, baffled tanks-I. Circulation time," Chemical Engineering Science, vol. 19, no. 3, pp. 201-208, 1964.

[61] A. W. Nienow, "On impeller circulation and mixing effectiveness in the turbulent flow regime," Chemical Engineering Science, vol. 52, no. 15, pp. 2557-2565, 1997.

[62] A. W. Patwardhan and J. B. Joshi, "Relation between flow pattern and blending in stirred tanks," Industrial and Engineering Chemistry Research, vol. 38, no. 8, pp. 3131-3143, 1999.

[63] K. Van Der Molen and H. R. E. Van Maanen, "Laser-Doppler measurements of the turbulent flow in stirred vessels to establish scaling rules," Chemical Engineering Science, vol. 33, no. 9, pp. 1161-1168, 1978. 

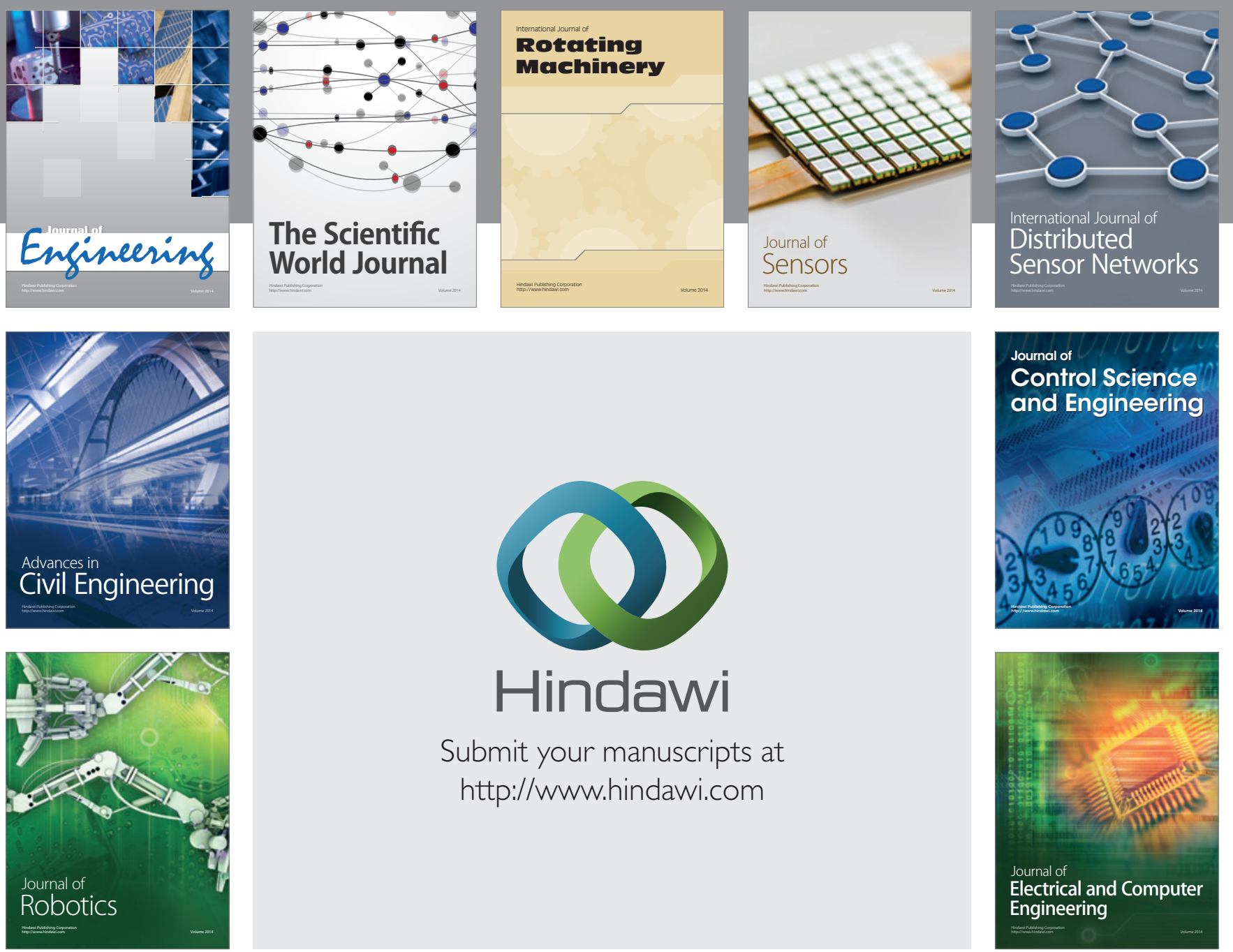

Submit your manuscripts at

http://www.hindawi.com
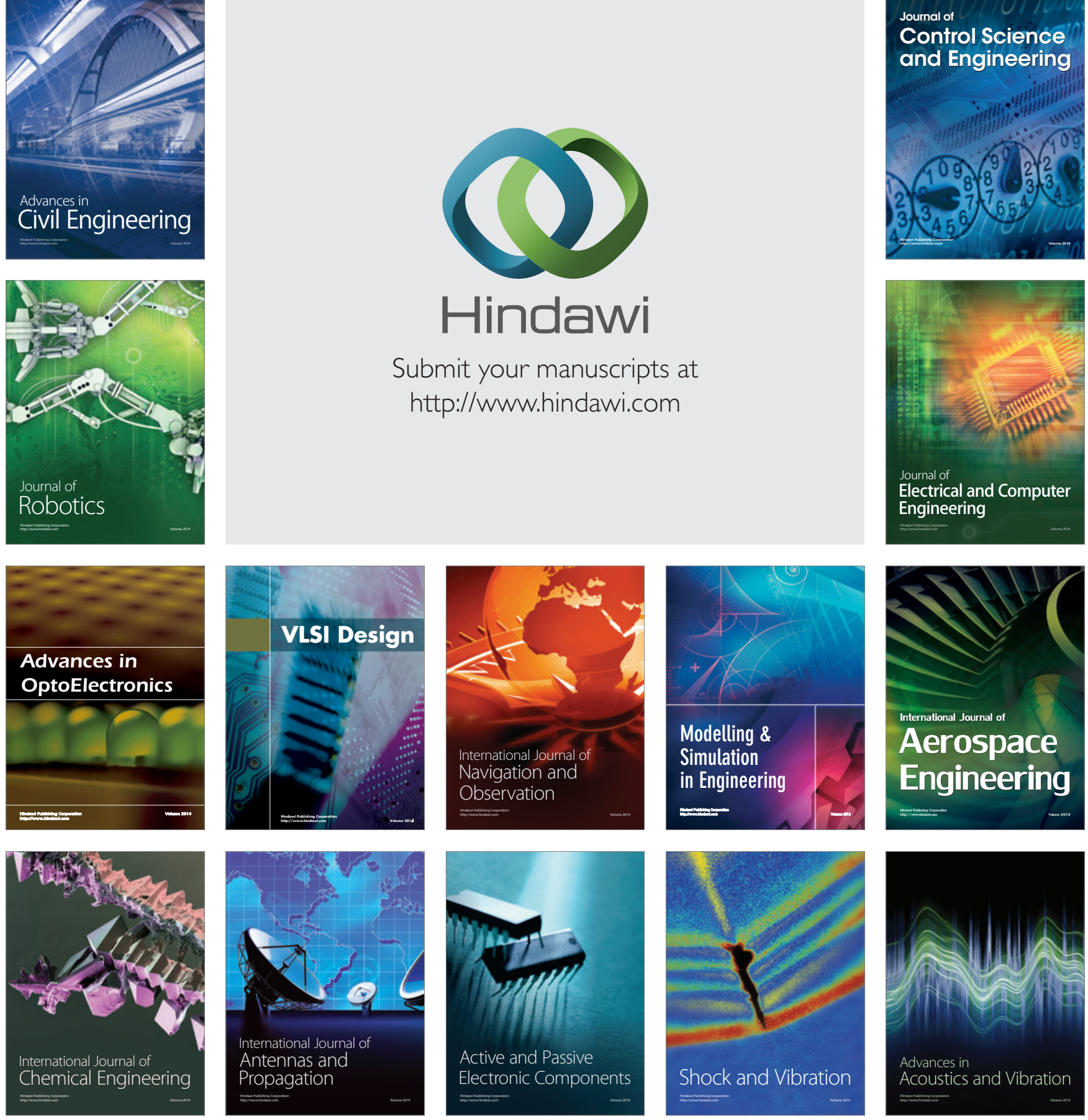